\title{
The Impact of Industrial Transfer on Industrial Structure Upgrading in Central China Take Hubei Province as an example
}

\author{
Chun Chen ${ }^{1}$, Hong Yuan ${ }^{1}$, Weiyan Lin ${ }^{1}$, Qing Xia*2 \\ ${ }^{1}$ College of Literature Law \& Economics Wuhan University of Science \& Technology Wuhan, China \\ ${ }^{2}$ School of Economics Wuhan Donghu University Wuhan, China
}

\begin{abstract}
In the construction plan of China (Hubei) pilot free trade zone issued by China (Hubei) pilot free trade zone in 2018, it is pointed out that industrial transfer should be orderly undertaken, which undoubtedly provides a strong institutional guarantee for Hubei to undertake industrial transfer. This paper analyzes the mechanism of industrial transfer on industrial structure upgrading: capital accumulation mechanism, technology progress mechanism, industry aggregation mechanism. At the same time through empirical analysis it is concluded that: build the double logarithm model of Hubei province to undertake industry shift after the provincial labor resources, science and technology innovation ability, industrial concentration degree of ascension for the upgrading of industrial structure in Hubei province has a certain role in promoting, especially the size of the capital and the increase of the number of high-tech talent to upgrade the industrial structure to promote the most significant effect. Therefore, the government should intensify efforts to introduce domestic and foreign capital, cultivate and attract more high-tech talents, focus on improving the quality of workers, expand the scale of industrial agglomeration within the province, and enhance the ability of scientific and technological innovation.
\end{abstract}

\section{INTRODUCTION AND LITERATURE REVIEW}

Under the vigorous promotion of the country and the continuous promotion of the world situation, undertaking industrial transfer has become a general trend of economic development. Hubei province is located in the central plains, east of the developed coastal cities in the east, west of the western countries to promote economic development region, in the process of undertaking industrial transfer, there is a link between the above and the following key role. However, how to better undertake industrial transfer in Hubei province, so as to optimize its industrial structure and promote the sustainable development of local economy is particularly important.

There are few studies on the relationship between the two mechanisms. However, the theory of industrial transfer and industrial structure has been quite mature. Metecalfe (2005) believes that the process of economic system transformation and industrial structure transformation is the process of economic development [1]. Antonelli (2006) proposed that technological change would have a certain impact on industrial dynamics, and at the same time, the change of industrial dynamics would in turn have an impact on the speed and direction of technological change [2]. Although such impact could not be achieved overnight, it could have an impact on the structural transformation of the economic system.

\section{ANALYsis on the Status Quo AND Problems}

Compared with surrounding provinces, Hubei province lacks a unified plan for industrial transfer, and the overall plan for industrial transfer within the province is insufficient. For each city in the province, it is basically a local unit that undertakes the transfer and undertaking of industries in the east. The Hubei provincial government has little unified guidance, which makes it difficult for Hubei province to formulate preferential policies with distinctive local characteristics and obvious competitive advantages in the competition of undertaking industrial transfer. On the other hand, compared with neighboring provinces, Hubei province started late to undertake industrial transfer and took relatively slow action, rarely taking the initiative to undertake industrial transfer. This is because Hubei province has a rich capital intensive manufacturing base, and it is one of the country's old industrial bases, which reduces the scale of labor intensive industries in the east.

Enterprises often pay the most attention to the supporting capacity of the local industry when choosing the residence. A good supporting capacity of the local

*Corresponding author's e-mail: 77218434@qq.com 
industry can reduce the production cost, promote technical cooperation and achieve scale effect. Although the capital intensive manufacturing industry in Hubei province has a good foundation, the shortage of the upstream and downstream industries affects the development of enterprises. Secondly, the quality of labor force in Hubei province is low, and the outmigration of high-quality labor force is large, leading to certain difficulties in undertaking high-end technology industries in Hubei province.

Finally, the market consumption ability of residents in the province is low, the purchasing power level is far lower than that of eastern cities, and the performance of marketing environment in Hubei province is not satisfactory.

For the undertaking area, sufficient and good element resources are one of the important conditions for an area to undertake industrial transfer. Due to water pollution, air pollution and shortage of land resources, environmental resources in Hubei province are becoming increasingly inadequate. First of all, the water pollution of the Yangtze river and the Han river, two big rivers in Hubei province, is serious. Second, because Hubei province is the country's old industrial base, industrial emissions over the years, resulting in serious air pollution in the province. Finally, there is a shortage of land resources in Hubei province. Much of the land in the plain has been occupied by native enterprises, leaving little land for transferred industries. Therefore, for Hubei province to undertake industrial transfer, land resources and industrial environment is not good.

TABLE I. Foreign TRAdE DEPENDENCE OF SiX ProvinCES

\begin{tabular}{llll}
\hline 2017 & $\begin{array}{c}\text { Total Import and } \\
\text { Export } \\
\text { (Thousand } \\
\text { dollars) }\end{array}$ & $\begin{array}{c}\text { Gross Regional } \\
\text { Product } \\
\text { (One hundred million } \\
\text { yuan) }\end{array}$ & $\begin{array}{c}\text { Foreign trade } \\
\text { dependence } \\
\text { (\%) }\end{array}$ \\
\hline Hubei & 46337190 & 35478.09 & $9.01 \%$ \\
Hunan & 36033297 & 33902.96 & $7.33 \%$ \\
Hunan & 77630090 & 44552.83 & $12.02 \%$ \\
Shanxi & 17186875 & 15528.42 & $7.64 \%$ \\
Anhui & 54021626 & 27018.00 & $13.80 \%$ \\
Jiangxi & 44338984 & 20006.31 & $15.29 \%$ \\
\hline
\end{tabular}

Source: Guoyan web http://data.stats.gov.cn/index.htm.

It is not difficult to see from TABLE I that compared with the other five provinces in central China, Hubei's foreign trade dependence is at the lower level of the six provinces, far from Henan, Anhui, Jiangxi and other places, let alone compared with the eastern cities with rapid economic development. In addition, Wuhan, the provincial capital, is the most open area in Hubei province. The total amount of foreign trade and the utilization scale of foreign capital in Wuhan account for a large proportion of the utilization in Hubei province, and the regional development is not coordinated. Compared with Wuhan, the development of other cities is even more backward. Compared with the developed cities in the east, Hubei province is far inferior to the developed cities in the east coast in terms of both economic externality and openness. Therefore, Hubei province still needs to further and comprehensively expand the pattern of opening to the outside world. On the other hand, as for the industry opening area of Hubei province, although the government of Hubei province has been focusing on accelerating the opening of the service industry to the outside world, expanding the scale of traditional service industry and strengthening the development of modern service industry, it hopes to attract more foreign investment. However, the industries attracting foreign investment in Hubei province are still mainly concentrated in traditional industries, and the service industry is still not as good as traditional industries. Therefore, the opening level of service industry in Hubei province has obviously been unable to meet the rapid economic development of the province.

Hubei province faces great challenges at home and abroad in undertaking industrial transfer and promoting industrial structure optimization and upgrading. On the one hand, since 2008, the rising cost of domestic workers has weakened the competitive advantage of domestic labor. Many enterprises have shifted their investment to Vietnam, Cambodia, Thailand and other countries and regions in southeast Asia where labor is relatively cheap. Recently, with the deepening of the trade war between China and the United States, many countries began to refuse to trade with China, which also created a huge obstacle for Hubei province to undertake international industrial transfer, and was very adverse to the development of the undertaking industry in Hubei province. On the other hand, Hunan, Henan, Anhui, Shanxi, Jiangxi and other provinces have their own advantages in undertaking industrial transfer due to their similar geographical location and development level, and there is great inter-regional competition. Hubei province will also face many challenges in undertaking industrial transfer.

\section{Mechanism of Action}

\section{A. Capital Accumulation Mechanism of Undertaking Industry Transfer}

The continuous accumulation of capital makes the capital not only used for transferring the internal use of the industry, but also used in the direction of high added value, making the capital flow from the industry with low production efficiency to the industry with high production efficiency. As a result, industries with low production efficiency in the province may not get financial support and face the risk of elimination.

\section{B. Technology Transfer and Technology Spillover Mechanism of Industry Transfer}

For Hubei province, take the initiative to undertake industrial transfer, and constantly obtain more industries higher than the local technical level, will certainly promote the development of the provincial industrial technical level, make the industry in Hubei province close to the high technical level, so as to upgrade the industrial structure. When Hubei province as the place to undertake the new transfer industry, the domestic 
supporting resources and the policies of the Hubei provincial government will be close to the industry in the province, and can make the supporting industries around drive the development. The upstream and downstream diffusion of technology is the vertical overflow of technology, which improves the technology of the upstream and downstream industries of the transferred industry and promotes the upgrading of industrial structure [3].

\section{Industrial Agglomeration Mechanism of Industrial Transfer}

When as undertake to take the initiative to actively undertake transfer of industry of Hubei province, because can make full use of the superior to turn out the factors of production in the province, to produce more competitive advantage, will attract more enterprises to choose the development in the province, has led to a "herd", therefore the enterprise of occupancy, can well formed industrial agglomeration effect [4]. Therefore, with the continuous improvement of transferred industrial technology, the cost advantage within the cluster is fully reflected, thus promoting the upgrading of industrial structure in Hubei province [5].

\section{Methods}

\section{A. Data and Modeling}

Through the above analysis, we can see that the undertaking industrial transfer to generate promote the upgrading of industrial structure, respectively, by undertaking industrial transfer of the accumulation of capital, technology transfer and overflow, and mechanism of industrial agglomeration, through specific job scale, investment scale, high technical human capital, the change of science and technology innovation, to display for the transfer of industries in Hubei province. At the same time, the efficiency of an area's economic development can roughly reflect the upgrading of the region's industrial structure, and the development of a region's tertiary industry can also roughly reflect the upgrading of the region's industrial structure. To this, this paper takes Hubei province's per capita GDP, and the added value of the third industry of Hubei province economic development efficiency and speed of the development of the third industry, and put the two values and the ratio of GDP as a quantitative index, it introduced as the upgrade of industrial structure in Hubei province be explained variables affecting estimation model, the above mentioned employment scale, investment scale, high technical human capital, science and technology innovation as the explained variable, two groups of general linear model is established, and two sets of double logarithm model.

$Y_{1}=c+\partial_{1} E M P+\partial_{2} F D I+\partial_{3} H U+\partial_{4} S C A+\partial_{5} S C I+\varepsilon_{1}(1)$

$Y_{2}=c+\beta_{1} E M P+\beta_{2} F D I+\beta_{3} H U+\beta_{4} S C A+\beta_{5} S C I+\varepsilon_{2}(2)$ $\ln \left(Y_{1}\right)=c+\lambda_{1} \ln (E M P)+\lambda_{2} \ln (F D I)+\lambda_{3} \ln (H U)+\lambda_{4} \ln (S C A)+\lambda_{5} \ln (S C I)+\varepsilon_{3}(3)$

$\ln \left(Y_{2}\right)=c+\gamma_{1} \ln (E M P)+\gamma_{2} \ln (F D I)+\gamma_{3} \ln (H U)+\gamma_{4} \ln (S C A)+\gamma_{5} \ln (S C I)+\varepsilon_{4}(4)$

Where, $Y_{l}$ represents per capita GDP, and $Y_{2}$ represents the proportion of added value of tertiary industry in Hubei's GDP. EMP represents the employment scale. In this paper, the total number of people employed in Hubei province in the whole year and the proportion of the total population in the province are used to calculate. FDI represents the scale of inward investment, which is measured by the proportion of total foreign investment and total domestic and foreign investment. What $H U$ represents is high technology manpower capital, the proportion that USES personnel of science and technology obtain employment to hold all obtain employment personnel will measure. SCA represents the industrial agglomeration scale, which is reflected by the proportion of the added value of industries above the scale in the total industrial output value in Hubei province. SCI represents the innovation capacity of science and technology, which is reflected by the proportion of provincial science and technology expenditure in GDP. $\varepsilon$ on behalf of the random error, $a$, $\beta, \lambda$ and $\gamma$ and coefficient of the model.

\section{B. Results}

According to the indicators and models proposed above, the author processed and calculated the data collected on the website of the national research website and the website of the National Bureau of Statistics for 22 years from 1996 to 2017, and then calculated the obtained data through the eviews.8 measurement software to get the following results.

According to TABLE II, it is not difficult to see that the model explains to some extent the impact of undertaking industrial transfer on industrial structure upgrading in Hubei province. Firstly, the coefficient of employment scale is positive, which proves that the expansion of employment scale can promote the upgrading of industrial structure. The fact that the scale coefficient of capital introduction is positive indicates that although Hubei province is not active enough to introduce domestic and foreign capital in the past 20 years, it still has a great positive effect on the industrial structure of Hubei province by introducing domestic and foreign undertaking industries. The coefficient of hightech human capital is positive, which indicates that a large number of high-quality talents moved in due to undertaking industrial transfer in Hubei province, which has a positive effect on the upgrading of industrial structure in Hubei province. The coefficient of industrial agglomeration scale is positive, which indicates that the industrial industry in Hubei province, which mainly undertakes industrial industry, has played a positive role in the upgrading of industrial structure. However, due to the data and various reasons, the obtained coefficient deviation is relatively large, so we conducted the experiment of model 3. 
According to TABLE III, model 2 also explains the impact of undertaking industrial transfer on industrial structure upgrading. The employment scale coefficient in model 2 is negative, which proves that Hubei province should make more efforts to undertake the transfer of high-tech industries, and improve the upgrading of industrial structure in Hubei province while expanding employment. Meanwhile, the coefficient of high-tech talent capital, industrial agglomeration and technological innovation ability is positive, which proves that the increase of these factors has promoted the industrial structure of Hubei province. Model 2 has a lower fitness value, so we introduce model 4.

It can be seen from TABLE IV and TABLE $\mathrm{V}$ that model 3 and model 4 have relatively improved on the basis of model 1 and model 2 in terms of data rationing values. Meanwhile, the results presented by model 3 and model 4 are similar, so we do the same analysis here. According to the model 3 and model 4, we can see how the employment scale coefficient value is negative, according to data research, in the period of data collection, the introduction of the industry of Hubei province in labor-intensive and resource-intensive industries, although the expanded employment, but expand employment with primary labor is given priority to, is not very good to improve industrial structure of Hubei province. The value of the scale of capital introduction is positive, which proves that Hubei province's continuous expansion of the scale of capital introduction has promoted the upgrading of industrial structure. The value of high-tech human capital is positive, which proves that the increase of high-tech talents in Hubei province can promote the upgrading of industrial structure in Hubei province. The coefficient of industrial agglomeration is positive, which indicates that good industrial agglomeration can promote the upgrading of industrial structure in Hubei province. The coefficient of scientific and technological innovation is positive, which also proves that good scientific and technological innovation in the province can promote the upgrading of industrial structure in the province.

Therefore, for Hubei province to undertake industrial transfer, the empirical analysis shows that the scale of introduced capital and the increase in the number of high-tech talents have the most significant promotion effect on the upgrading of industrial structure, so more efforts should be made to introduce domestic and foreign capital and cultivate and attract more high-tech talents. Similarly, the empirical results show that the increase of these two factors can positively promote the upgrading of industrial structure. Therefore, the government should expand the scale of industrial agglomeration in the province and enhance the ability of scientific and technological innovation. Finally, we should strengthen the promotion of labor quality while expanding employment, because the result of empirical analysis shows that the employment scale of Hubei province is relatively loose with the structure due to the low quality of labor force.

TABLE II. MODEL 1.

\begin{tabular}{lllllll}
\hline & $\boldsymbol{E M P}$ & $\boldsymbol{F D I}$ & $\boldsymbol{H U}$ & $\boldsymbol{S C A}$ & $\boldsymbol{S C I}$ & $\boldsymbol{c}$ \\
\hline Coefficient & 377.0417 & 43.56292 & 3042.368 & 151.3591 & -2149.257 & -11768.56 \\
T value & -3.696168 & 3.662472 & 1.553214 & 0.281229 & -1.5369 & -3.696168 \\
$\mathrm{P}$ value & 0.0000 & 0.0846 & 0.3035 & 0.3432 & 0.1451 & 0.0022 \\
\hline $\mathrm{R} 2=0.985944 \mathrm{~F}=210.4354 \mathrm{DW}=1.093887$ & & & & \\
\hline
\end{tabular}

TABLE III. MODEL 2.

\begin{tabular}{lllllll}
\hline & $\boldsymbol{E M P}$ & $\boldsymbol{F D I}$ & $\boldsymbol{H U}$ & $\boldsymbol{S C A}$ & $\boldsymbol{S C I}$ & $\boldsymbol{c}$ \\
\hline Coefficient & -2.460371 & 0.096832 & 251.0955 & -0.122356 & 74.07742 & 22.69675 \\
T value & -6.190592 & 0.894120 & 6.019923 & -0.440146 & 5.598340 & 1.845804 \\
$\mathrm{P}$ value & 0.00001 & 0.3854 & 0.00001 & 0.6661 & 0.0001 & 0.0848 \\
\hline $\mathrm{R} 2=0.815051 \mathrm{~F}=13.22073 \mathrm{DW}=1.450913$ & & & & \\
\hline
\end{tabular}

TABLE IV. MODEL 3

\begin{tabular}{lllllll}
\hline & $\boldsymbol{E M P}$ & $\boldsymbol{F D I}$ & $\boldsymbol{H U}$ & $\boldsymbol{S C A}$ & $\boldsymbol{S C I}$ \\
\hline Coefficient & -0.874258 & 2.199550 & 3.044212 & 0.698585 & 0.212583 \\
T value & -3.966869 & 2.787015 & 7.583315 & 1.676094 & 1.697137 \\
P value & 0.0012 & 0.00138 & 0.00001 & 0.1144 & 0.1103
\end{tabular}


TABLE V. MODEL 4.

\begin{tabular}{lllllll}
\hline & $\boldsymbol{E M P}$ & $\boldsymbol{F D I}$ & $\boldsymbol{H U}$ & $\boldsymbol{S C A}$ & $\boldsymbol{S C I}$ & $\boldsymbol{c}$ \\
\hline Coefficient & -0.12790 & 1.051636 & 2.087320 & 0.923421 & 0.094213 & 23.30423 \\
T value & -0.758772 & 3.245503 & 4.288128 & 2.559747 & 0.958979 & 7.357735 \\
$\mathrm{P}$ value & 0.4597 & 0.0054 & 0.0006 & 0.0218 & 0.3528 & 0.00001 \\
\hline $\mathrm{R} 2=0.990358 \mathrm{~F}=308.1273 \mathrm{DW}=1.327771$ & & & &
\end{tabular}

\section{Conclusions}

Through the above empirical analysis, it can be seen that the scale of introduced capital and the increase of hightech talents have the most significant promotion effect on the upgrading of industrial structure. Moreover, the employment scale of Hubei province is relatively loose with the industrial structure due to the low quality of the labor force.

\section{A. Make Full Use of Provincial Resource Advantage}

First of all, should according to each region in the province of resources endowment, regional transportation, industrial foundation, the specific situation of the development goals, set a conform to the scientific planning of regional development of undertaking industrial transfer and scheme, actively encourage around for receiving of high and new technology industry, improve the supporting resources for new and high technology industries. Through empirical analysis, we know that the increase of innovative talents plays a positive role in promoting the upgrading of industrial structure in Hubei province, so we should make full use of the advantages of innovative talents in Hubei province. At the same time, government more should make full use of resources in the province, according to the characteristics of the dominated by industry in Hubei province, making full use of the advantage status in the province of the industry such as industry, agriculture, mining, enact and perfect relevant industry supporting policy and planning, more attention should be paid to the cultivation and development of green industry, perfect the industry planning of form a complete set of green industry.

\section{B. Innovate the Way of Attracting Investment}

Through empirical analysis, we know that Hubei province to strengthen the scale of investment for the upgrading of the province's industrial structure has an important impetus. Therefore, Hubei provincial government should take the historical experience of industrial transfer at home and abroad as the foundation, continuously study earnestly, and actively innovate the way of attracting investment. We should improve the platform for attracting investment within the province, strengthen the hardware construction of the development zone, the most important platform for undertaking industrial transfer, insist on improving the construction of all kinds of facilities in the park, actively upgrade the management of the development zone, and innovate the management system.

\section{Strengthen Oversight of Environmental Protection and Enhance Our Awareness of Environmental Protection}

At the same time, the government should also carry out strict control over the development of unreasonable resources, strictly prevent many wastes caused by the unreasonable use of resources, protect natural forest areas, soil and water through ecological management projects, strictly curb the occurrence of disorderly development behaviors that destroy the ecology, and actually protect the ecological environment. We will continue to build a mechanism for industrial technology acceptance, apply and promote energy conservation, emission reduction and ecological and environmental protection technologies, vigorously develop low-carbon economy and circular economy, and provide strong technical support for industrial acceptance.

\section{ACKNOWLEDGMENT}

Special thanks to the teachers of College of Literature Law \& Economics for their support.

\section{REFERENCES}

1. J. S. Metealfe, R. Ramlogan, "Competition and the Regulation of Economic Development," The Quarterly Review of Economics and Finance, vol. 45, pp. 215-235, 2005.

2. C. Antonelli, "Localized Technological Change and Factor Markets :Constraints and Inducements to Novation,". Structural Change and Economic Dynamics, vol. 2, pp. 224247, 2006.

3. Y. Liu, "Research on Undertaking Eastern Industrial Transfer And Analysis Of Countermeasures In Hubei Province," Economic Research Guide, vol. 08, pp. 67-71, 2012.

4. $\mathrm{X} . \mathrm{Xu}$ and J. Fu, "Research On Undertaking Industrial Transfer and Promoting the Updating of Industrial Structure in Henan Province," Modern Business Trade Industry, vol. 19, pp. 3-4, 2019.

5. J. Zhou and Y. Li, "Effects of Industrial Transfer on Optimizing and Upgrading of Industry Structure in Undertaking Region-Taking Anhui Province as an Example," Journal of Shenyang University (Social Science), vol. 04, pp. 454-458, 2014. 